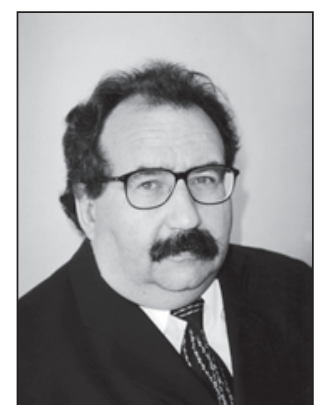

ПОВОРОЗНЮК В.В.

ГУ «Институт геронтологии имени Д.Ф. Чеботарева НАМН Украины» Украинский научно-медицинский центр проблем остеопороза, г. Киев

\title{
ПРОБЛЕМА ТРОМБОЭМБОЛИИ В ЛЕЧЕНИИ ПАЦИЕНТОВ С ОСТЕОПОРОЗОМ
}

\section{Актуальность проблемы}

Проблема венозной тромбоэмболии (ВТЭ) - одна из важных в практическом здравоохранении. Среди всех случаев ВТЭ наиболее значимыми являются тромбозы глубоких вен нижних конечностей (ТГВНК) и легочные эмболии (ЛЭ). Средний риск ВТЭ среди представителей европеоидной расы - 108 на 100000 пациенто-лет [25, 65], что составляет 250000 случаев ежегодно среди белокожего населения США. Уровень риска ВТЭ среди афроамериканского населения США такой же или, по данным некоторых авторов, выше, а среди азиатов и коренных американцев - несколько ниже [32, 78]. Проведенные недавно исследования в США выявили от 900000 до 1 млн случаев первичных и повторных ВТЭ ежегодно [22, 43, 66]. Риск смерти после перенесенной ВТЭ составляет около 30 \% в течение последующих 30 дней, у 1/3-1/2 пациентов развиваются повторные ВТЭ [28, 52]. Экономические затраты на лечение ВТЭ существенны и составляют 10-16 тыс. долларов на человека, в связи с чем в США ежегодно тратится свыше 2 млн долларов для лечения новых и повторных ВТЭ [68]. Несмотря на значимый прогресс в лечении, риск ВТЭ за последние 25 лет не изменился [25].

Согласно многочисленным исследованиям, риск ВТЭ значимо возрастает при старении [12, 25, 43, 65], составляя соответственно 1/10 000 при рождении и 1/100 у пациентов старше 80 лет [66]. Частота ВТЭ существенно увеличивается с возрастом как для ЛЭ, так и ТГВНК [12, 25, 65]. Риск смерти среди больных с симптоматической ЛЭ в раннем периоде после ее развития в 18 раз выше по сравнению с соответствующими показателями у пациентов с ТГВНК [26]. Почти у четверти пациентов с ЛЭ манифестация инцидента проявляется фактом внезапной смерти. По данным некоторых авторов, ежегодная частота смертей, связанных с ЛЭ, в США, возможно, превышает соответствующие показатели, связанные с инфарктом миокарда и инсультом [22].

Риск ВТЭ выше у мужчин (130 на 100 000) по сравнению с женщинами (110 на 100 000), соотношение пока- зателя у мужчин и женщин - соответственно 1,2 : 1 [25, 65]. Уровень риска несколько выше у женщин в репродуктивном периоде, однако после 45 лет он значимо возрастает у мужчин. Риск ЛЭ увеличивается с возрастом пропорционально как у мужчин, так и женщин [65]. Поскольку риск ЛЭ с возрастом увеличивается более значимо, чем риск ТГВНК, увеличивается также и риск летальных исходов ВТЭ [27, 66].

\section{Патофизиология тромбозов и тромбоэмболии}

Тромбоз - процесс прижизненного свертывания крови в просвете сосуда или в полостях сердца. Образующийся при этом сгусток крови называют тромбом [43]. Чрезмерное тромбообразование приводит к сужению просвета сосуда или к его окклюзии.

Свертывание крови наблюдается в сосудах после смерти, при этом выпавшие плотные массы крови называют посмертным сгустком крови. Кроме того, свертывание крови происходит в тканях при кровотечении из поврежденного сосуда и представляет собой естественный гемостатический механизм, направленный на остановку кровотечения при повреждении сосуда.

Процесс свертывания крови совершается в виде каскадной реакции при последовательной активации белков-предшественников, или факторов свертывания, находящихся в крови или тканях. Различают внутреннюю (кровь) и внешнюю (ткань) свертывающие системы. Помимо системы свертывания, существует и противосвертывающая система крови, которая обеспечивает регуляцию гемостаза - жидкого состояния крови в сосудистом русле в нормальных условиях. Исходя из этого тромбоз представляет собой проявление нарушенной регуляции системы гемостаза.

\footnotetext{
(C) Поворознюк В.В., Григорьева Н.В., 2013

(c) «Боль. Суставы. Позвоночник», 2013

(с) Заславский А.Ю., 2013
} 
Тромбоз отличается от свертывания крови, однако это различие несколько условно, поскольку в обоих случаях запускается каскадная реакция свертывания крови. Tромб представляет собой сгусток крови, который всегда прикреплен к эндотелию кровеносного сосуда в месте его повреждения и состоит из слоев связанных между собой тромбоцитов, нитей фибрина и форменных элементов крови, а кровяной сгусток содержит беспорядочно ориентированные нити фибрина с расположенными между ними тромбоцитами и эритроцитами. В зависимости от строения и внешнего вида различают белый, красный, смешанный и гиалиновый тромб. По отношению к просвету сосуда различают пристеночный или обтурирующий (закупоривающий) тромб.

В механизмах тромбообразования выделяют четыре стадии: агрегации (склеивание тромбоцитов), коагуляции (коагуляция фибриногена и образование фибрина), агглютинации (склеивание эритроцитов) и преципитации (осаждение белков плазмы).

В 1865 году $R$. Virchow описал сочетание патологических факторов, являющихся основным пусковым механизмом внутрисосудистого образования тромбов и известных как триада Вирхова. Она включает в себя изменение реологических свойств крови (состояние гиперкоагуляции), травму сосудистой стенки (повреждение эндотелия) и замедление кровотока (стаз). Огромное количество факторов могут провоцировать развитие внутрисосудистого образования тромбов, при этом любой из них реализуется через один или несколько механизмов триады Вирхова. Каждый из этих факторов в разных случаях заболевания может иметь разное значение.

\section{Факторы риска тромбоэмболии}

Приблизительно 30 \% пациентов с перенесенными ВТЭ в последующие 10 лет имеют повторные события ВТЭ [24, 62]. Риск повторных ВТЭ изменяется с течением времени и является самым высоким в течение первых 6-12 мес. после факта ВТЭ. Независимые предикторы повторных ВТЭ - мужской пол, увеличение возраста и индекса массы тела, неврологические заболевания с нижним парапарезом, а также активная фаза онкологических заболеваний [1, 12, 24, 46, 62]. Дополнительные предикторы - наличие «идиопатической» ВТЭ [1], выявление волчаночного антикоагулянта или антифосфолипидных антител [35, 61], дефицит антитромбина, протеинов C или S [72], возможно длительное увеличение уровня плазменного D-димера фибрина [50], а также остаточные явления тромбоза глубоких вен [53].

Факторы, способствующие появлению тромбоза, в большинстве случаев носят приобретенный характер. К факторам, способствующим развитию тромбоза, в частности ТГВНК, относят травму или оперативное вмешательство, иммобилизацию нижних конечностей, ожирение, беременность и роды, пожилой возраст, заболевания почек и печени, а также ранее перенесенные тромбозы.

Как отмечалось выше, патогенез тромбоза сложен и обусловлен взаимодействием местных и общих провоцирующих факторов. К местным факторам относят изменения сосудистой стенки, замедление и нарушение тока крови; к общим - нарушение регуляции свертывающей и противосвертывающей системы крови, изменение состава крови и величины электростатического потенциала между кровью и внутренней стенкой сосуда.

Возраст. С увеличением возраста значительно увеличивается риск ВТЭ [12, 25, 43, 65, 67], что связывают со снижением мобильности пациента, увеличением выраженности нарушений кровотока и венозного стаза, уменьшением эластичности и тонуса сосудистой стенки за счет структурных изменений, что усиливает тромбогенную дилатацию вен. Прогрессирующие с возрастом функциональные изменения в системе гемостаза обусловливают развитие «претромботического» состояния, проявляющегося повышением свертывающей активности и снижением фибринолиза.

Tравма и операция. В последние годы высокую распространенность венозных тромбозов связывают с возрастающим числом оперативных вмешательств и расширением их объема, применением общего обезболивания с использованием миорелаксантов, увеличением среди оперируемых лиц пожилого возраста с тяжелой сопутствующей патологией. Так, показано, что на 1,2 млн операций на органах брюшной полости, производимых в США в течение года у больных в возрасте старше 40 лет, развивается 158 тыс. случаев ТГВНК $[38,56]$.

Иммобилизация нижних конечностей. Венозный тромбоз обычно возникает в клапанах или венозных синусах икроножной и камбаловидной мышц. По данным M. Verstraete et al. (1984), при использовании кинофлебографии показано, что скорость кровотока в икроножной и камбаловидной мышцах нижних конечностей у здоровых людей в покое ниже, чем в других отделах, что еще более выражено при иммобилизации и горизонтальном положении. Признаки тромбоза глубоких вен отмечены клинически у $12 \%$ больных с параплегией. В первые 3 мес. после инсульта $3 \%$ больных с цереброваскулярными нарушениями умирают от тромбоэмболии легочной артерии (ТЭЛА).

В последние годы в США появился новый термин «телевизионный тромбофлебит», который часто используют в отношении пожилых людей, которые длительно находятся перед телевизионными экранами в креслах, причем ребро сиденья затрудняет у них венозный отток от нижней половины туловища. Длительное нахождение нижних конечностей в согнутом положении, в том числе и при вождении автомобиля, также может способствовать сдавлению подколенной вены, затруднению оттока крови и повышению риска ТГВНК.

Кроме того, в литературе существует термин «синдром экономического класса», впервые описанный I.S. Symington и B.H.R. Stack в 1977 г. [70], при изучении спровоцированных длительными авиаперелетами тромбоэмболических осложнений, связанных с длительной компрессией магистральных вен и затруднением венозного кровотока в конечностях [36]. В более поздних исследованиях, проведенных I. Vjjrhoeve и F. Bruyninch (1984; 1988), при введении добровольцам перед 5-часовым полетом фибриногена, меченного ${ }^{125} \mathrm{I}$, у 7 \% обследованных по окончании рейса обнаружено его накопление «растущим» тромбом в венах голени.

Анестезию в настоящее время также относят к факторам риска, предрасполагающим к развитию ВТЭ. Пока- 
зано, что общая анестезия с применением мышечных релаксантов значительно чаще сопровождается тромбозом глубоких вен нижних конечностей, чем при использовании регионарных методов анестезии (спинальная, эпидуральная, проводниковая), при этом решающую роль играют более длительная иммобилизация конечности и выключение мышечной помпы.

Венозные тромбозы в анамнезе. Наличие в анамнезе сведений об эпизоде венозного тромбоза в 3-4 раза увеличивает риск его повторного развития после травмы или операции $[67,79]$. У таких больных возрастает опасность повторных тромбозов после прекращения антикоагулянтной терапии. В патогенезе рецидивирующего флеботромбоза играет роль дефицит ингибиторов коагуляции (антитромбин III, протеин С) [79].

Ожирение. Данные литературы свидетельствуют об увеличении риска послеоперационного тромбоза при ожирении, причинами которого могут быть нарушение фибринолитической активности, снижение физической активности и более длительный срок иммобилизации в послеоперационном периоде.

По данным F.R. Rosendaal et al. [58], факторами риска венозного тромбоза у женщин являются возраст, предшествующие тромбозы, беременность, послеродовой период, прием эстрогенов, хирургические вмешательства, антифосфолипидный синдром, онкологические заболевания, иммобилизация, длительные путешествия, а также нарушения коагуляционных свойств крови (дефицит антитромбина, протеина С и S, протромбина 20210A, FV Leiden, дисфибриногенемия, высокий уровень протромбина и факторов свертывания FVIII, FIX, FXI, TAFI). Факторами риска артериального тромбоза у женщин являются возраст, курение, гипертензия, прием эстрогенов, антифосфолипидный синдром, гипергомоцистеинурия, гиперхолестеринемия, сахарный диабет, снижение физической активности, а также нарушения коагуляционных свойств крови (протромбин 20210A (?), FV Leiden (?), высокий уровень FVIII (?) и FIX (?)).

Клиническое значение тромбозов определяется быстротой развития, локализацией, распространенностью и исходом. К благоприятным исходам относятся асептический фибринолиз тромба (возникающий под влиянием протеолитических ферментов лейкоцитов) или его организация, обызвествление или петрификация. К неблагоприятным исходам тромбоза относятся отрыв тромба или его части и превращение в тромбоэмбол (является источником тромбоэмболии); септическое расплавление тромба (при попадании в тромботические массы гноеродных бактерий, что ведет к тромбобактериальной эмболии сосудов различных органов и тканей, в частности при сепсисе).

Размер и локализация тромбов определяют клиническую картину тромбозов. Так, тромбоз венозных синусов твердой мозговой оболочки как осложнение отита или мастоидита может привести к расстройству мозгового кровообращения, тромбоз воротной вены - к портальной гипертензии и асциту, тромбоз селезеночной вены - к спленомегалии. При тромбозе почечных вен в ряде случаев развиваются нефротический синдром или венозные инфаркты почек, при тромбофлебите печеноч- ных вен - болезнь Бадда - Киари, а при тромбозе брыжеечных вен - гангрена кишечника. Характерную клиническую картину дает тромбофлебит (флебит, осложненный тромбозом) вен нижних конечностей, а флеботромбоз (тромбоз вен) становится источником ТЭЛА.

Самым опасным осложнением венозного тромбоза является тромбоэмболия легочных артерий. Она заключается в отрыве части тромба, миграции тромбоэмбола с током крови через правые отделы сердца в легочную артерию с последующей ее обструкцией. Источником легочных тромбоэмболов являются тромбы из венозной системы нижних конечностей и таза.

\section{Применение лекарственных средств и тромбозы}

В настоящее время накоплен ряд данных о том, что некоторые лекарственные средства и лечебно-диагностические манипуляции (длительные внутривенные инфузии и др.) создают условия для тромбоза и эмболии. Однако, учитывая большую частоту тромбоэмболии при различных заболеваниях и оперативных вмешательствах, очевидно, что роль лекарственных средств и инструментальных процедур в развитии тромбоэмболии во многих случаях вспомогательная, а нередко ее вообще сложно доказать.

В настоящее время к лекарственным средствам, возможно, способствующим развитию тромбоэмболии легких, относят пероральные противозачаточные средства (ПОПЗС), кортикостероиды, адренокортикотропный гормон, диуретики (хлортиазид, спиронолактоны), контрастные масляные средства и др.

Возможная связь между тромбозами и приемом ПОПЗС была заподозрена еще в 1961 г. после случая легочной эмболии со смертельным исходом у двух молодых женщин в послеродовом периоде, принимавших эновид. После этого W.M. Jordan (1961) описал случай применения эновида при рецидивирующем эндометриозе с развитием эмболии артерий легких (с инфарктами в легких).

В 1962 году I. Lorentz впервые сообщил о случае ишемического инсульта при использовании ПОПЗС, а в 1963 году J. Boyce, J.W. Fawcett, E.W.P. Noall сообщили о первом случае инфаркта миокарда на фоне приема ПОПЗС.

В настоящее время, несмотря на результаты проведенных многочисленных исследований, данный вопрос все еще остается спорным. По мнению ряда авторов, опасность развития ТГВНК и ЛЭ (а также и тромбозов мозга) значительно выше при применении ПОПЗС. Они проявляются в основном клинической картиной инфарктов легких или сосудов головного мозга. С другой стороны, на основании проспективных исследований, охвативших большое число женщин, их роль отвергается.

В последнее время в литературе отмечены случаи тромбоза легочной артерии или ее главных ветвей, приводящего к смерти, у детей с нефротическим синдромом, леченных преднизоном и диуретическими средствами. Также при лечении кортикостероидами описаны случаи жировых эмболий почек, легких, мозга и других органов, в развитии которых может играть роль стеатоз печени, который развивается при использовании больших доз кортикостероидов. 
В последние годы установлена связь между приемом препаратов фенотиазина, хлоразина, ларгактила и риском тромбозов. Согласно исследованиям M. Meyler et al., частота тромбозов при лечении хлорпромазином в 8 раз больше, чем при лечении другими лекарственными средствами.

В некоторых исследованиях отмечено повышение частоты ЛЭ у психиатрических больных, что связывают с применением некоторых психофармакологических лекарственных средств, однако высказывается мнение о том, что развитие тромбозов, очевидно, связано со снижением физической активности больных. Отдельные авторы отмечают повышенный риск тромбозов при хинидинотерапии. Как редкое проявление лекарственных поражений была известна смертельная эмболия при дополнительном лечении тамоксифеном больных с раком молочной железы.

Еще одним фактором развития ятрогенных тромбозов может быть внезапное прекращение применения антикоагулянтов, особенно гепарина. Введение витамина К во время лечения кумаринами также приводит к повышению риска тромбозов и эмболии. Часто эмболии возникают у наркоманов при введении наркотиков в одну и ту же вену, что связано с развитием местного флебита.

Патогенез лекарственных легочных тромбозов и эмболии различен и зависит в значительной степени от лекарственного средства - во многих случаях они являются результатом его основного фармакологического действия. Так, тромбоэмболический эффект диуретиков объясняют уменьшением объема циркулирующей крови. Однако у больных с сердечно-сосудистой патологией значение имеют и некоторые изменения факторов свертывания крови (повышение уровня проакселерина, фибриногена) и часто наблюдающийся у них артериосклероз, который может активировать агглютинирующий тромбоциты фактор.

В патогенезе поражений следует учитывать, что если диуретики (дихлортиазид) вызывают тромбозы вследствие дегидратации, то ПОПЗС и глюкокортикоиды влияют на свертывающую систему крови и на снижение тонуса венозной стенки.

Эмболии легких, вызванные использованием контрастных рентгеновских препаратов, нередко являются жировыми эмболиями и обусловлены попаданием в ве-

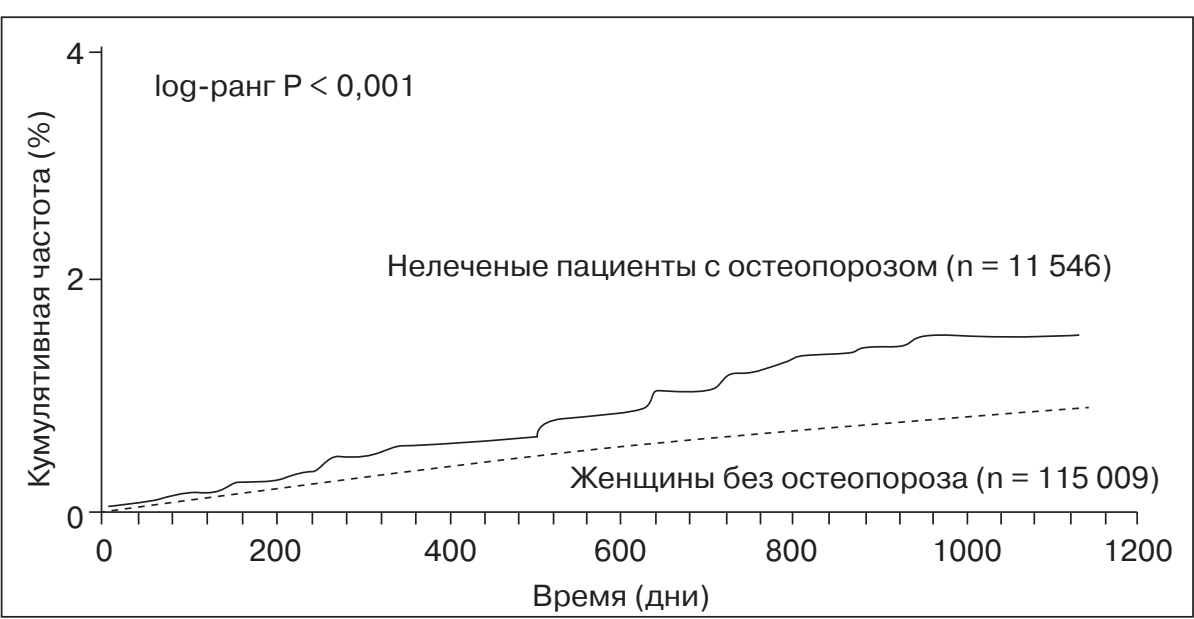

Рисунок 1. Кумулятивная частота первой ВТЭ у здоровых пациенток без остеопороза и нелеченых больных с остеопорозом (nо методу Kaplan - Meier) [8] нозное русло масляных контрастных средств (инфаркты легких после ангиокардиографии, лимфографии и др.).

Клиническая картина лекарственных эмболий легких такая же, как и при нелекарственных тромбоэмболиях. Наблюдаются проявления как массивных, быстро приводящих к смерти эмболий, так и симптомов более или менее типичных легочных инфарктов. При жировых эмболиях вследствие применения контрастных средств картина нередко бывает нечеткой, хотя иногда наблюдается и типичная картина легочного инфаркта.

Проблема ВТЭу пациентов с остеопорозом. В ретроспективном когортном исследовании с использованием базы General Practice Research Database (GPRD) изучена частота тромбоэмболии у здоровых пациентов и больных с остеопорозом, применявших различные виды антиостеопоротических препаратов, в том числе стронция ранелат и алендронат натрия [8].

Анализ проводили в 2 группах в зависимости от наличия остеопороза (115 009 здоровых пациенток и 58242 больных с остеопорозом, из которых 11546 не получали антиостеопоротические препараты). Определяли частоту ВТЭ в расчете на 1000 пациенто-лет и время до первого события ВТЭ с использованием кривой Kaplan - Meier. Анализ проводили с использованием регрессионной Сохмодели для сравнения риска ВТЭ между когортами, в том числе с учетом фактора возраста, поскольку известно, что он является важным для риска ВТЭ [16, 29, 39, 57, 79].

Частота ВТЭ у нелеченых больных с остеопорозом была выше $(3,4 \%)$ по сравнению с данными здоровых пациентов $(1,6 \%)$, а риск ВТЭ был значительно больше (относительный риск (OP) 1,75; 95\% ДИ 1,09-1,84) в когорте нелеченых больных с остеопорозом по сравнению с показателем у здоровых пациентов. Он оставался значимым и после поправки на возраст $(\mathrm{HR}=1,43 ; 95 \%$ ДИ 1,10 $1,86)$. В модели с учетом всех анализируемых факторов риска различия были еще более значимыми $(\mathrm{HR}=1,38 ; 95 \%$ ДИ 1,03-1,86). На рис. 1 представлена кривая Kaplan Meier, демонстрирующая совокупный риск первого эпизода ВТЭ в течение периода исследования.

Ежегодная частота ВТЭ составила 3,2 на 1000 пациенто-лет у леченых пациентов с остеопорозом против 5,6 на 1000 пациенто-лет при отсутствии антиостеопоротического лечения (табл. 1)

Кроме того, в данном исследовании было продемонстрировано, что частота ВТЭ увеличивается с возрастом как у женщин с остеопорозом, так и у здоровых пациенток: соответственно 2,4 и 4,3 на 1000 пациенто-лет - в возрасте от 50 до 75 лет; 5,2 и 7,2 на 1000 пациенто-лет - у женщин в возрасте от 75 до $80 ; 6,1$ и 8,3 на 1000 пациенто-лет - у женщин старше 80 лет.

Препарать кальция и витамина $D$ и риск тромбоэмболий. В настоящее время установлено, что кальций и его 
соединения влияют не только на процессы минерализации и формирования скелета, но и на агрегатное состояние крови, гемодинамику и микроциркуляцию.

Ионы кальция активно участвуют в процессе свертывания крови. Для агрегации тромбоцитов, помимо их активации различными другими факторами, необходимо наличие ионов кальция $\left(\mathrm{Ca}^{2+}\right)$, поскольку агрегация тромбоцитов связана с внутриклеточным обменом $\mathrm{Ca}^{2+}$ (мобилизация кальция из тубулярной системы в цитоплазму).

Регуляция активации тромбоцитов в значительной мере осуществляется за счет высвобождения $\mathrm{Ca}^{2+}$ из депо тромбоцитов. В результате этого повышается концентрация кальция в цитозоле клетки, активируются протеинкиназы и, в конечном итоге, происходит фосфорилирование регуляторных белков внутри тромбоцитов. Кроме того, повышение $\mathrm{Ca}^{2+}$ в цитозоле клетки стимулирует фосфолипазу $\mathrm{A}_{2}$, вызывая высвобождение арахидоновой кислоты - предшественника ТХА.

Высвобождение $\mathrm{Ca}^{2+}$ регулируется несколькими факторами. При связывании тромбина и других агонистов с соответствующими рецепторами на мембране тромбоцитов образуются промежуточные соединения, которые стимулируют высвобождение $\mathrm{Ca}^{2+}$ из депо. ТХА, повышает уровень внутриклеточного $\mathrm{Ca}^{2+}$, связываясь на поверхности тромбоцитов со своим рецептором, который подавляет активность аденилатциклазы, снижая тем самым продукцию цАМФ и повышая выход $\mathrm{Ca}^{2+}$ из депо. В отличие от этого продуцируемый эндотелиальными клетками простациклин стимулирует активность аденилатциклазы, повышает концентрацию цАМФ в тромбоцитах и тормозит секрецию $\mathrm{Ca}^{2+}$ из депо.

Общеизвестно, что действие тромбокиназы и превращение протромбина в тромбин осуществляется только в присутствии ионов кальция. Кроме того, только в присутствии $\mathrm{Ca}^{2+}$ фактор IX активируется фактором XIa, а факторы VII и XIII активируются тромбином. Фактор X активируется на поверхности активированных тромбоцитов фактором Тэнасе и фактором VIIа в присутствии тканевого фактора и $\mathrm{Ca}^{2+}$.
В последнее время в литературных источниках появились сведения, что прием препаратов кальция увеличивает риск осложнений со стороны сердечно-сосудистой системы.

По данным рандомизированного исследования The Women's Health Initiative calcium-vitamin $D$ randomized controlled trial, в котором изучено влияние дополнительного потребления кальция (1000 мг/д) и витамина D (400 ME/д) в течение 7 лет на показатели общей смертности [40], риск общей смертности составил 0,91 (95\% ДИ 0,83-1,01), однако это снижение было недостоверным, как и снижение риска смерти от инсульта. Для 29942 женщин моложе 70 лет этот показатель составлял 0,89 (95\% ДИ 0,79-1,01), для 6340 женщин 70 лет и старше $-0,95$ (95\% ДИ $0,80-1,12 ; \mathrm{p}=0,10)$. При разделении женщин в зависимости от уровня потребления кальция (1-499, 500-999, 1000 мг/д и более) не установлено достоверных отличий в показателях риска сердечно-сосудистых событий [6].

В анализе исследований, опубликованном S.M. Shah et al. в январе 2010 года [64], изучена роль длительного (более 2 лет) дополнительного потребления кальция и витамина D на риск сердечно-сосудистых событий и частоту смерти у 9910 женщин в возрасте 60-89 лет. Было продемонстрировано, что у пациентов, получавших более 600 мг/д Са в течение 2 лет, не установлено увеличения риска инфаркта миокарда, инсультов и общей смертности по сравнению с показателями пациентов, принимавших кальций более 90 дней (относительный риск составил 0,82; $95 \%$ ДИ $0,67-1,01)$.

В многочисленных исследованиях последних лет показано, что дефицит витамина D является важным фактором риска гипертензии, ожирения, диабета и метаболического синдрома, а его дополнительный прием может значимо снижать частоту сердечно-сосудистых событий $[9,41,45,47,51,63]$.

Однако в последнее время появилось противоположное мнение, ставящее под сомнение безопасность при-

Таблица 1. Частота ВТЭ у леченых женщин с остеопорозом по сравнению с нелечеными пациентками [8]

\begin{tabular}{|c|c|c|}
\hline Показатели & $\begin{array}{c}\text { Леченые пациенты с остеопорозом } \\
\text { (n = 115 009) }\end{array}$ & $\begin{array}{l}\text { Нелеченые пациенты с остеопорозом } \\
\qquad(\mathrm{n}=11546)\end{array}$ \\
\hline Больные с ВТЭ (n) & 767 & 61 \\
\hline Ежегодная заболеваемость (на 1000 пациенто-лет) & 3,2 & 5,6 \\
\hline Относительный риск (95\% ДИ) & \multicolumn{2}{|c|}{$1,75(1,09-1,84)$} \\
\hline \multicolumn{3}{|c|}{ Модель, корригированная по возрастуа } \\
\hline HR (станд. ошибка) & \multicolumn{2}{|c|}{$1,43(0,13)$} \\
\hline 95\% доверительный интервал & \multicolumn{2}{|c|}{$1,10-1,86$} \\
\hline Р-значение & \multicolumn{2}{|c|}{0,007} \\
\hline \multicolumn{3}{|c|}{ Полностью корригированная модель } \\
\hline HR (станд. ошибка) & \multicolumn{2}{|c|}{$1,38(0,15)$} \\
\hline 95\% доверительный интервал & \multicolumn{2}{|c|}{$1,03-1,86$} \\
\hline Р-значение & \multicolumn{2}{|c|}{0,030} \\
\hline
\end{tabular}

Примечания: ВТЭ - венозная тромбоэмболия (в т.ч. тромбоз глубоких вен, тромбоэмболия легочной артерии или тромбоз вен сетчатки); HR - отношение рисков; HR - между группами на основании регрессионной модели Сох, корригированной по возрасту; $\mathrm{H}^{b}$ — между группами на основании регрессионной модели Сох, корригированной по всем изучаемым факторам. 
менения препаратов кальция у людей старших возрастных групп [5-7]. По результатам проведенного в июле 2010 года метаанализа [5] 15 исследований было показано, что прием кальция без витамина D ассоциирован с увеличением риска инфаркта миокарда $(\mathrm{OP}=1,27$; 95\% ДИ 1,01-1,59; $\mathrm{p}=0,038)$. Также установлено недостоверное увеличение риска инсультов (ОР $=1,20 ; 95 \%$ ДИ 0,96-1,50; $\mathrm{p}=0,11)$, внезапной смерти $(\mathrm{OP}=1,18$; 95\% ДИ 1,00-1,39; $\mathrm{p}=0,057)$ и общего риска смерти $(\mathrm{OP}=1,09 ; 95 \%$ ДИ 0,96-1,23; p=0,18). В 13 из анализируемых 15 исследований кальций применялся в виде монотерапии по сравнению с группой плацебо и только в одном исследовании сравнивали эффект монотерапии кальцием и комбинированной терапии (кальций и витамин D), в связи с чем установленный авторами отрицательный эффект монотерапии кальцием не может быть экстраполирован на исследования по комбинированному его приему с витамином D.

В ответ на данный метаанализ сразу же появились обзоры исследований, опровергающие отрицательное влияние кальция на риск сердечно-сосудистых событий. Таким образом, на сегодняшний день отрицательное влияние комбинированного приема препаратов кальция и витамина D на сердечно-сосудистую систему не доказано, а сами они остаются обязательным компонентом любой схемы лечения остеопороза. Кроме того, ни в одном исследовании, подтвердившем отрицательное влияние дополнительного приема кальция и витамина D на риск заболеваний сердечно-сосудистой системы и инсульта, не продемонстрировано его отрицательное влияние на риск тромбообразования.

Заместительная гормональная терапия (ЗГТ) и риск венозных тромбозов. Еще при первом изучении побочных эффектов ЗГТ в 1974 г. было отмечено некоторое преобладание среди пациентов с ВТЭ женщин, получавших ЗГТ, однако этот факт не нашел подтверждения в последующих исследованиях, особенно при использовании трансдермальных форм ЗГТ. Позже в исследованиях типа «случай - контроль» и проспективных наблюдательных исследованиях был отмечен более высокий риск развития венозных тромбозов при использовании ЗГТ (в 2-4 раза выше, чем у женщин, не получающих ее) (рис. 2) [58].

По данным многих исследований, наибольший риск развития ВТЭ отмечается в первый год приема ЗГТ. Этот факт в значительной степени свидетельствует о существовании дополнительных факторов риска, в частности скрытой генетической тромбофилии (мутация FV Leiden, протромбина G20210A и др.) или антифосфолипидного синдрома [58]. В исследованиях, проведенных F.R. Rosendaal et al. [56-58], было показано, что если риск ТГВНК при наличии мутации FV Leiden или протромбина G20210A повышается в 4,5 раза, а при использовании ЗГТ - в 3,6 раза, то при их сочетании отмечается увеличение риска в 11 раз.

Таким образом, по мнению многих авторов [1, 58], ЗГТ, так же как и ПОПЗС, обладает синергичным эффектом с генетической и приобретенной тромбофилией в отношении риска развития ВТЭ.

В настоящее время данные о влиянии ЗГТ на отдельные факторы свертывающей системы крови весьма про- тиворечивы, однако известно, что наряду с активацией коагуляции активируется и фибринолиз, о чем свидетельствует повышение уровня t-PА и снижение PAI-1.

Согласно результатам некоторых исследований прием пероральных неконъюгированных эстрогенов повышает уровень фактора свертывания VII, в то время как прием комбинированных эстроген-гестагенных препаратов или трансдермальный путь введения эстрогенов не влияет на уровень фактора VII или даже способствует его некоторому снижению.

По данным ряда авторов, снижение уровня фибриногена и фактора VII при использовании монотерапии эстрогенами и комбинированных препаратов ЗГТ может нивелироваться отрицательным влиянием ЗГТ на естественные антикоагулянты - снижением АТ III, протеинов С и S. B некоторых исследованиях отмечается повышение уровня протеина С и отсутствие влияния на протеин $\mathrm{S}$ при использовании ЗГТ, при этом большинство исследований свидетельствуют о появлении резистентности к АРС $[1,58]$.

Многие исследования свидетельствуют о повышении маркеров тромбофилии, так же как F1+2, фибринопептида А и растворимого фибрина на фоне ЗГТ. Несмотря на различные эффекты ЗГТ на отдельные факторы свертывания, все они свидетельствуют об активации свертывающей системы. Кроме того, повышение уровней Dдимера и комплексов «плазмин - антиплазмин» свидетельствует о том, что при ЗГТ повышена не только коагуляционная активность, но также активизирован и фибринолиз [1].

В некоторых исследованиях не обнаружено повышения уровней F1+2, TAT и D-димера на фоне приема ЗГТ. Наряду с этим при активации коагуляционного каскада и фибринолиза не обнаруживается корреляционная связь между уровнем повышения маркеров тромбинемии и фибринолиза. Это свидетельствует о том, что их активация на фоне приема ЗГТ не является ответом на повышение коагуляционной активности. В некоторых исследованиях показано, что ЗГТ снижает уровень липопротеина $(\alpha)$, который является независимым фактором риска атеросклероза и ишемической болезни сердца (ИБС), что, возможно, частично объясняет снижение PAI-1 на фоне ЗГТ и активацию фибринолиза [1].

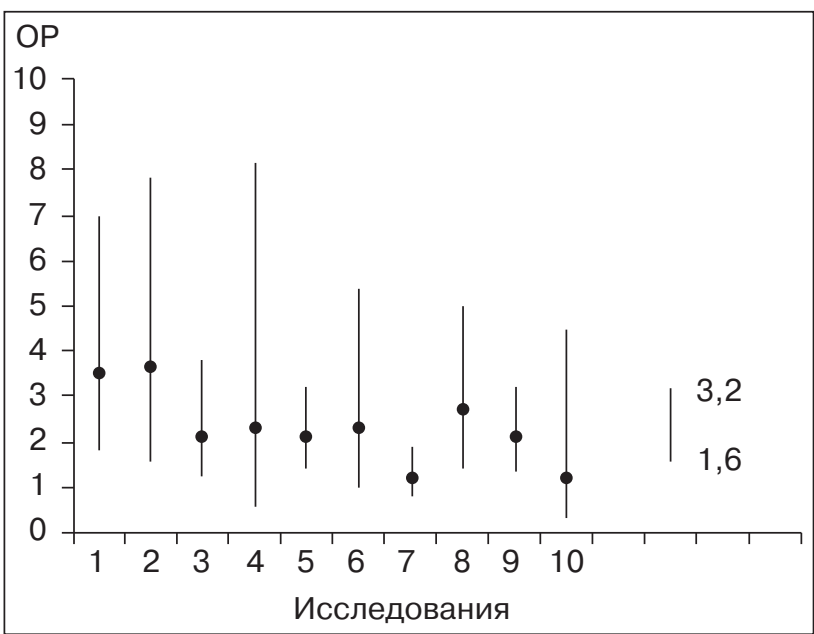

Рисунок 2. Относительный риск ВТЭ на фоне терапии ЗГТ (результаты 10 исследований) [58] 
В настоящее время оценка роли ЗГТ в первичной и вторичной профилактике сердечно-сосудистых заболеваний проводилась в 10 рандомизированных контролируемых исследованиях $[10,15,30,31,33,74,76,77,80$, 81], изучавших риски и преимущества ЗГТ у постменопаузальных женщин. Результаты трех исследований, проведенных в США [33, 80, 81], двух - в Великобритании $[10,15]$ и одного - в Эстонии [74] не выявили положительного эффекта ЗГТ в предупреждении сердечнососудистой патологии.

В большом рандомизированном плацебо-контролируемом исследовании WHI(Women's Health Initiative), целью которого было изучение эффективности эстрогенгестагенной терапии в профилактике сердечно-сосудистых заболеваний и переломов шейки бедренной кости, а также определение риска развития рака молочной железы и толстого кишечника, связанного с применением ЗГТ, рандомизировано 16608 постменопаузальных женщин в возрасте 50-79 лет с интактной маткой из 40 клинических центров США [11]. Пациентки принимали либо конъюгированный этинилэстрадиол (КЭЭ) по 0,625 мг в сочетании с медроксипрогестероном ацетата (МПА) по 2,5 мг ежедневно по непрерывной схеме (8506 пациентов) либо плацебо (8102 пациента). В данном исследовании в первые 2 года отмечено достоверное увеличение как частоты инсультов, инфарктов миокарда, так и венозных тромбозов и легочной эмболии у пациентов, принимающих ЗГТ, по сравнению с группой плацебо [60, 81]. Однако было показано, что комбинированная ЗГТ увеличивает риск сердечно-сосудистых событий у женщин за счет возрастной группы 70-79 лет в первый год терапии [44]. С учетом факта превышения рисков по сравнению с преимуществами ЗГТ исследование было преждевременно прервано через 5,2 года. Позже была также прервана другая часть данного исследования, изучавшая эффективность и безопасность монотерапии эстрогенами по сравнению с плацебо (период наблюдения составил 6,8 года), в связи с увеличением риска инсультов на фоне отсутствия достоверных различий в показателях общей сердечно-сосудистой заболеваемости и рака молочной железы [80].

Другое рандомизированное плацебо-контролируемое исследование HERS (Heart and Estrogen/Progestin Replacement Study), завершенное в 1998 году, проводилось с целью оценки эффективности ЗГТ во вторичной профилактике сердечно-сосудистых заболеваний [11]. В данном исследовании приняли участие 2763 постменопаузальные женщины с ИБС и интактной маткой (средний возраст 67 лет; ранг 50-80 лет). Были выделены 2 группы пациенток, получавших плацебо или комбинированную ЗГТ (КЭЭ 0,625 мг/д + МПА 2,5 мг/д). Результаты исследования HERS были оглашены через 4,1 года вместо планируемых 5 лет и показали увеличение числа венозных тромбозов и отсутствие положительного эффекта в отношении профилактики сердечно-сосудистых заболеваний [20]. Кроме того, в данном исследовании установлено повышение риска артериальных тромбозов у пациенток с генетически обусловленной и приобретенной (антифосфолипидные антитела) тромбофилией на фоне приема ЗГТ.
Повышение риска венозных тромбозов на фоне применения ЗГТ установлено также в рандомизированном исследовании EVTET у женщин с венозными тромбозами в анамнезе. Исследование было прекращено досрочно на основании полученных результатов: частота рецидивов тромбозов составила $10,7 \%$ в группе пациенток с тромбозами в анамнезе на фоне 3ГТ и 2,3 \% - в группе плацебо. Относительный риск тромбозов составил 7,77 (95\% ДИ 1,00-60,53), легочных эмболий $-2,92$ $(95 \%$ ДИ 0,31-27,35) [11]. Все случаи тромбозов были отмечены в течение первого года приема ЗГТ. Большинство женщин с рецидивом венозного тромбоза на фоне приема ЗГТ имели генетически обусловленный (мутация фактора V Leiden) или приобретенный (антифосфолипидные антитела) дефект гемостаза [1].

В исследованиях HERS и NHS (Nurses' Health Study) продемонстрировано, что положительный эффект ЗГТ в профилактике сердечно-сосудистых заболеваний в значительной степени зависит от функционального состояния эндотелия, в связи с чем положительные эффекты ЗГТ отмечаются у относительно молодых женщин в постменопаузе без заболеваний сердечно-сосудистой системы в анамнезе.

По данным многочисленных исследований, более высокий риск артериальной или ВТЭ при назначении ЗГТ связан с такими факторами риска, как возраст, курение, сахарный диабет, артериальная гипертензия, гиперлипидемия, гипергомоцистеинемия и семейный анамнез тромбоэмболии.

В мультицентровом рандомизированном плацебоконтролируемом исследовании WISDOM (Women's Iternational Study of long-Duration Jestrogen after Menopause), в котором 5692 женщины в возрасте 50-69 лет (средний возраст $62,8 \pm 4,8$ года) получали лечение только эстрогенами (0,625 КЭЭ перорально) или комбинированную ЗГТ (0,625 КЭЭ + 2,5/5,0 мг МПА перорально), изучена роль ЗГТ в развитии сердечно-сосудистых событий, остеопоротических переломов и рака молочной железы (планируемая длительность исследования - 10 лет). Однако исследование было преждевременно прекращено (период наблюдения после начала терапии составил 11,9 мес. (ранг 7,1-19,6; 6498 пациенто-лет)) после публикации результатов исследования Women's Health Initiative.

В данном исследовании установлено, что у женщин, принимающих комбинированную терапию $(\mathrm{n}=2196)$, по сравнению с группой плацебо $(\mathrm{n}=2189)$ зарегистрированы (табл. 2) значительно более высокие показатели больших сердечно-сосудистых событий (7 и 0 случаев, 26,9 и 0 на 10000 пациенто-лет, $\mathrm{p}=0,016)$ и ВТЭ (22 и 3 случая, 85,1 и 11,5 на 10000 пациенто-лет, отношение рисков составило 7,36 (2,2-24,6, p < 0,001) и незначительное снижение риска остеопоротических переломов (155,3 и 226,2 на 10000 пациенто-лет, отношение рисков $0,69(046-1,03, \mathrm{p}=0,07)$ на фоне отсутствия достоверных различий в показателях риска рака молочной железы, цереброваскулярных событий и показателя общей смертности. При сравнении вышеперечисленных показателей риска в группе, получавшей монотерапию эстрогенами или комбинированную ЗГТ, достоверных различий не выявлено. 
В данном исследовании авторы сделали вывод, что ЗГТ повышает риск сердечно-сосудистых заболеваний и ВТЭ, если она начата в позднем постменопаузальном периоде. В настоящее время необходимо проведение мультицентровых рандомизированных исследований по изучению показателей безопасности у молодых женщин, начавших ЗГТ в перименопаузе или раннем постменопаузальном периоде.

В связи с вышесказанным многие исследователи придерживаются мнения о том, что при назначении ЗГТ следует учитывать возраст пациентки и соответственно оценивать степень повреждения коронарных артерий. В условиях «здорового», функционирующего эндотелия ЗГТ как эстрогенсодержащими, так и комбинированными препаратами у здоровых женщин в постменопаузе значительно улучшает эндотелиальную функцию, вазодилататорный ответ, липидный профиль, тормозит экспрессию медиаторов воспаления и, возможно, снижает уровень гомоцистеина - важнейшего фактора атеросклероза и заболеваний коронарных сосудов. Пожилой возраст и атеросклеротическое повреждение сосудов сопровождаются снижением функциональной активности эндотелия (антитромботической) и, в частности, снижением количества эстрогеновых рецепторов, что, соответственно, значительно снижает потенциальный кардиои эндотелиопротективный эффект ЗГТ. Таким образом, эффекты ЗГТ в настоящее время все больше рассматриваются в связи с концепцией так называемого «здорового» эндотелия [1-3].

Учитывая вышесказанное, вопрос об эффективности ЗГТ в профилактике сердечно-сосудистых осложнений в настоящее время остается нерешенным и требует проведения дальнейших исследований.

Селективные модуляторы эстрогенных рецепторов (SERM) и риск тромбоэмболии. В настоящее время согласно обновленным Европейским рекомендациям по лечению остеопороза (2012) препараты группы SERM являются препаратами первой линии при проведении терапии. Однако накопленные результаты многоцентровых рандомизированных исследований показывают, что SERM (тамоксифен, ралоксифен) могут увеличивать риск ВТЭ, при этом отрицательный эффект такого препарата, как торемифен, в настоящее время не доказан [49].

В мультицентровом рандомизированном плацебо-контролируемом исследовании Multiple Outcomes of Raloxifene Evaluation (MORE) [19] показано, что относительный риск ВТЭ через 2 года приема ралоксифена составил 6,6 [21], тогда как результаты дальнейших постмаркетинговых исследований (медиана при лечении ралоксифеном в исследованиях составила 2,3 года) свидетельствуют о менее выраженном повышении риска ВТЭ $(\mathrm{OP}=4,7)[21]$.

В международном рандомизированном плацебоконтролируемом исследовании Raloxifene Use for The Heart (RUTH), проведенном в период 1998-2006 гг. с целью сравнения влияния ралоксифена и плацебо на частоту коронарных событий и инвазивного рака молочной железы у женшин с повышенным риском коронарных событий, обследована 10101 женщина (возраст 55 лет и старше) из 177 центров в 26 странах. Пациентки получали перорально 60 мг/д ралоксифена $(\mathrm{n}=5044)$ или плацебо ( $\mathrm{n}=5057)$ [49].

Таблица 2. Риск венозных тромбоэмболий и смертности по данным исследования WISDOM [75]

\begin{tabular}{|c|c|c|c|c|c|}
\hline \multirow[b]{2}{*}{ Показатели } & \multirow{2}{*}{$\begin{array}{c}\text { Количество паци- } \\
\text { ентов всех групп } \\
(n=5692)\end{array}$} & \multicolumn{2}{|c|}{$\begin{array}{c}\text { Комбинированная терапия по срав- } \\
\text { нению с группой плацебо }\end{array}$} & \multicolumn{2}{|c|}{$\begin{array}{c}\text { Комбинированная терапия по сравне- } \\
\text { нию с терапией эстрогенами }\end{array}$} \\
\hline & & $\begin{array}{c}\text { Комбинирован- } \\
\text { ная терапия } \\
(n=2196)\end{array}$ & $\begin{array}{c}\text { Плацебо } \\
\text { (n=2189) }\end{array}$ & $\begin{array}{c}\text { Комбинирован- } \\
\text { ная терапия } \\
(\mathrm{n}=815)\end{array}$ & $\begin{array}{c}\text { Эстрогентерапия } \\
(\mathrm{n}=826)\end{array}$ \\
\hline \multicolumn{6}{|c|}{ Венозные тромбоэмболии } \\
\hline Тромбоз глубоких вен & 18 & 13 & 1 & 5 & 3 \\
\hline Легочная эмболия & 14 & 10 & 2 & 2 & 1 \\
\hline $\begin{array}{l}\text { Тромбоэмболия с летальным ис- } \\
\text { ходом }\end{array}$ & 3 & 2 & 0 & 0 & 1 \\
\hline Любая из вышеперечисленных & 30 & 22 & 3 & 7 & 3 \\
\hline Уровень риска (95\% ДИ)* & $46,4(32,4-66,3)$ & $85,1(56,0-129,2)$ & $11,5(3,7-35,7)$ & $84,3(40,2-176,9)$ & $35,3(11,4-109,5)$ \\
\hline $\begin{array}{l}\text { Уровень риска (95\% ДИ), } \\
\text { значение р }\end{array}$ & & $\begin{array}{c}7,36(2,20-24,60) \\
p<0,001\end{array}$ & $\begin{array}{c}2,39(0,62-9,24) \\
p=0,19\end{array}$ & & \\
\hline $\begin{array}{l}\text { Отношение рисков (95\% ДИ), } \\
\text { значение р }\end{array}$ & & $\begin{array}{c}0,88(0,49-1,56) \\
p=0,65\end{array}$ & $\begin{array}{c}1,16(0,42-3,20) \\
p=0,78\end{array}$ & & \\
\hline \multicolumn{6}{|c|}{ Смерть } \\
\hline Сердечно-сосудистые события & 1 & 0 & 0 & 0 & 1 \\
\hline Цереброваскулярные события & 1 & 1 & 0 & 0 & 0 \\
\hline Венозные тромбоэмболии & 3 & 2 & 0 & 0 & 1 \\
\hline Все смерти & 15 & 8 & 5 & 1 & 2 \\
\hline $\begin{array}{l}\text { Уровень риска (95\% ДИ), } \\
\text { значение р }\end{array}$ & $23,1(13,9-38,3)$ & $30,7(15,3-61,3)$ & $19,2(8,0-46,1)$ & $11,9(1,7-84,7)$ & $23,5(5,9-94,0)$ \\
\hline $\begin{array}{l}\text { Отношение рисков (95\% ДИ), } \\
\text { значение р }\end{array}$ & & $\begin{array}{c}1,60(0,52-4,89) \\
p=0,40\end{array}$ & $\begin{array}{c}0,51(0,05-5,58) \\
p=0,57\end{array}$ & & \\
\hline
\end{tabular}

Примечание: * - уровень на 10000 женщино-лет. 
В данном исследовании продемонстрировано, что общая частота инсультов (на 100 пациенто-лет) не отличается в группе, принимавшей ралоксифен $(0,95)$ или плацебо $(0,86 ; \mathrm{p}=0,30)$, однако зарегистрирована более высокая частота инсультов, приводивших к летальному исходу (соответственно в группах 0,22 и 0,15 ; $\mathrm{p}=0,0499)$. Кроме того, среди зарегистрированных 174 случаев ВТЭ (107 в группе, принимавшей ралоксифен, и 71 - в группе плацебо) частота ВТЭ (на 100 пациентолет) составила соответственно 0,39 и 0,27 ( $\mathrm{p}=0,02)$. Абсолютное увеличение риска, связанное с приемом ралоксифена, составило 0,12 за 100 пациенто-лет. Частота легочной эмболии, ТГВНК и тромбоза сетчатки не отличалась в группах, а среди 15 летальных ВТЭ все были связаны с легочной эмболией. При этом показатели смертности от ВТЭ у женщин с высоким риском сердечно-сосудистых событий не отличались в группах, принимавших ралоксифен или плацебо (табл. 3).

Кумулятивный риск ВТЭ при лечении ралоксифеном по результатам исследования $R U T H$ представлен на рис. 3 [49].

В проведенном исследовании при post hoc анализе не установлено достоверных различий между группами за исключением более высокого показателя частоты инсультов у курящих женщин, принимавших ралоксифен. Последующий анализ относительно риска ВТЭ в зависимости от дополнительных факторов его риска представлен на рис. 4 [49].

Таким образом, в исследовании RUTH, несмотря на более высокую частоту ВТЭ у женщин с высоким коронарным риском, не установлено повышение показателей общей смертности и смертности вследствие ВТЭ, в связи с чем сделан вывод об относительной безопасности проводимой терапии.

Стронция ранелат и риск венозных тромбозов. На сегодняшний день стронция ранелат (бивалос) является препаратом первой линии в лечении постменопаузального остеопороза и остеопороза у мужчин с повышенным риском переломов. По результатам рандомизированных мультицентровых исследований SOTI и TROPOS, частота ВТЭ при использовании стронция ранелата не увеличивалась в течение 5 лет наблюдения $(\mathrm{n}=3352)$ и составила $2,7 \%$. В даль-

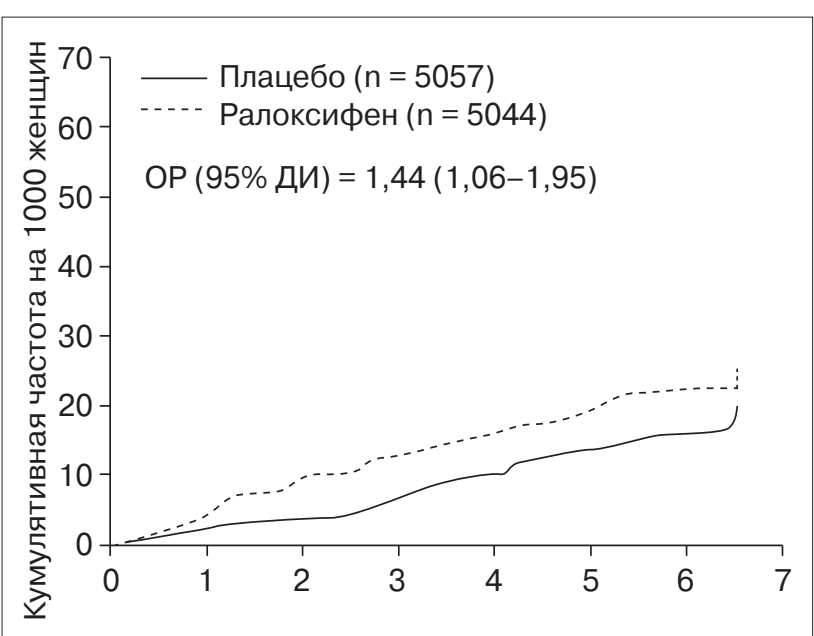

Рисунок 3. Кумулятивный риск венозных тромбоэмболий при лечении ралоксифеном [49]

нейшей открытой фазе этих исследований в течение 5-10 лет наблюдения $(\mathrm{n}=237)$ данный показатель составил 2,5\% [54].

Относительный риск ВТЭ при применении стронция ранелата в рандомизированных исследованиях составил 1,5 [21, 54], а в дальнейших постмаркетинговых исследованиях - 1,1 [21].

В большом когортном мультицентровом европейском исследовании с участием 12702 женщин, получавших стронция ранелат (средний период лечения $25,2 \pm 13,7$ мес.), риск ВТЭ составил 2,1 на 1000 пациенто-лет (95\% ДИ 1,6-2,8).

Еще в одном постмаркетинговом исследовании изучена безопасность стронция ранелата на основании активного извещения со стороны пациентов и врачей о регистрации его побочных эффектов, основанных на данных UK General Practice Research Database (GPRD) $[17,21]$. База данных $G P R D$ - одна из наибольших в мире компьютеризированных баз данных регистрации медицинской документации практического здравоохранения Великобритании, содержащая данные более 3,4 млн пациентов. В анализ о безопасности включены 1574 пациентки (средний возраст 77 лет, ранг 4095 лет), принимавших стронция ранелат с 01.12.2004

Таблица 3. Заболеваемость и относительный риск развития инсульта и ВТЭ [49]

\begin{tabular}{|c|c|c|c|c|}
\hline \multirow[b]{2}{*}{ Конечная точка } & \multicolumn{2}{|c|}{ Количество событий (в год, \%) } & \multirow{2}{*}{$\begin{array}{l}\text { Относительный риск (HR, } \\
95 \% \text { ДИ) }\end{array}$} & \multirow[b]{2}{*}{$\mathbf{P}$} \\
\hline & $\begin{array}{l}\text { Группа плацебо } \\
(\mathrm{n}=5057)\end{array}$ & $\begin{array}{c}\text { Группа ралоксифена } \\
(\mathrm{n}=5044)\end{array}$ & & \\
\hline Все ВТЭ-события & $71(0,27)$ & $103(0,39)$ & $1,44(1,06-1,95)$ & 0,02 \\
\hline Легочная эмболия & $24(0,09)$ & $36(0,14)$ & $1,49(0,89-2,49)$ & 0,13 \\
\hline Тромбоз глубоких вен & $47(0,18)$ & $65(0,24)$ & $1,37(0,94-1,99)$ & 0,10 \\
\hline $\begin{array}{l}\text { Внутричерепной тромбоз (вены } \\
\text { сетчатки) }\end{array}$ & $6(0,02)$ & $8(0,02)$ & $1,32(0,46-3,80)$ & 0,61 \\
\hline Общая смертность & $595(2,25)$ & $554(2,07)$ & $0,92(0,82-1,03)$ & 0,16 \\
\hline $\begin{array}{l}\text { Все смерти от сердечно-сосуди- } \\
\text { стых событий }\end{array}$ & $355(1,34)$ & $362(1,35)$ & $1,01(0,87-1,17)$ & 0,91 \\
\hline Некоронарогенные события & $81(0,31)$ & $107(0,40)$ & $1,31(0,98-1,74)$ & 0,07 \\
\hline Цереброваскулярные (инсульт) & $39(0,15)$ & $59(0,22)$ & $1,49(1,00-2,24)$ & 0,05 \\
\hline ВТЭ & $5(0,10)$ & $10(0,20)$ & $1,98(0,68-5,79)$ & 0,20 \\
\hline
\end{tabular}


по 31.12.2006 г. в течение более чем 3000 пациенто-лет (средний период лечения составил 12,6 года).

В данном анализе не установлено достоверное повышение риска ВТЭ, который составил 1,1 в отличие от данных, полученных при использовании другого антиостеопоротического препарата - ралоксифена, при использовании которого зарегистрировано достоверное увеличение риска ВТЭ до 4,7 (табл. 4). В течение периода наблюдения было зарегистрировано 2 случая легочной тромбоэмболии и ни одного случая тромбоэмболии вен нижних конечностей.

При сравнении частоты ВТЭ в ретроспективном когортном исследовании с использованием базы GPRD у больных с остеопорозом в зависимости от вида антиостеопоротического лечения (принимавших стронция ранелат или алендронат натрия) не выявлено достоверных различий между группами (табл. 5), в том числе и после поправки на фактор возраста и другие изучаемые факторы. Частота ВТЭ в группе больных с остеопорозом, принимавших стронция ранелат, составила 4,2 \%, а в груп- пе больных, принимавших алендронат натрия, $3,8 \%[8]$.

Частота ВТЭ в группе, принимавшей стронция ранелат, составила 7,0 на 1000 пациенто-лет, с ОР 1,15 (95\% ДИ $0,63-2,1)$ и 1,09 (95\% ДИ 0,60-2,01) в модели с поправкой на возраст и не отличалась от показателей нелеченых женшин с остеопорозом. В группе больных, получавших алендронат натрия, частота ВТЭ составила 7,2 на 1000 пациенто-лет и 1,10 (95\% ДИ 0,81-1,50) в модели с поправкой на возраст и с учетом всех анализируемых факторов 0,92 (95\% ДИ 0,63-1,33) и не отличалась от соответствующих показателей нелеченых больных.

В данном исследовании показатель общей смертности достоверно не отличался в зависимости от проводимого лечения и составил 2,9 \% в группе больных, принимавших стронция ранелат, и 4,0 \% в группе больных, получавших алендронат натрия.

При анализе частоты ВТЭу пациентов в зависимости от текущего или предшествующего приема антиостеопоротических препаратов не установлены достоверные различия анализируемых показателей в обеих группах.

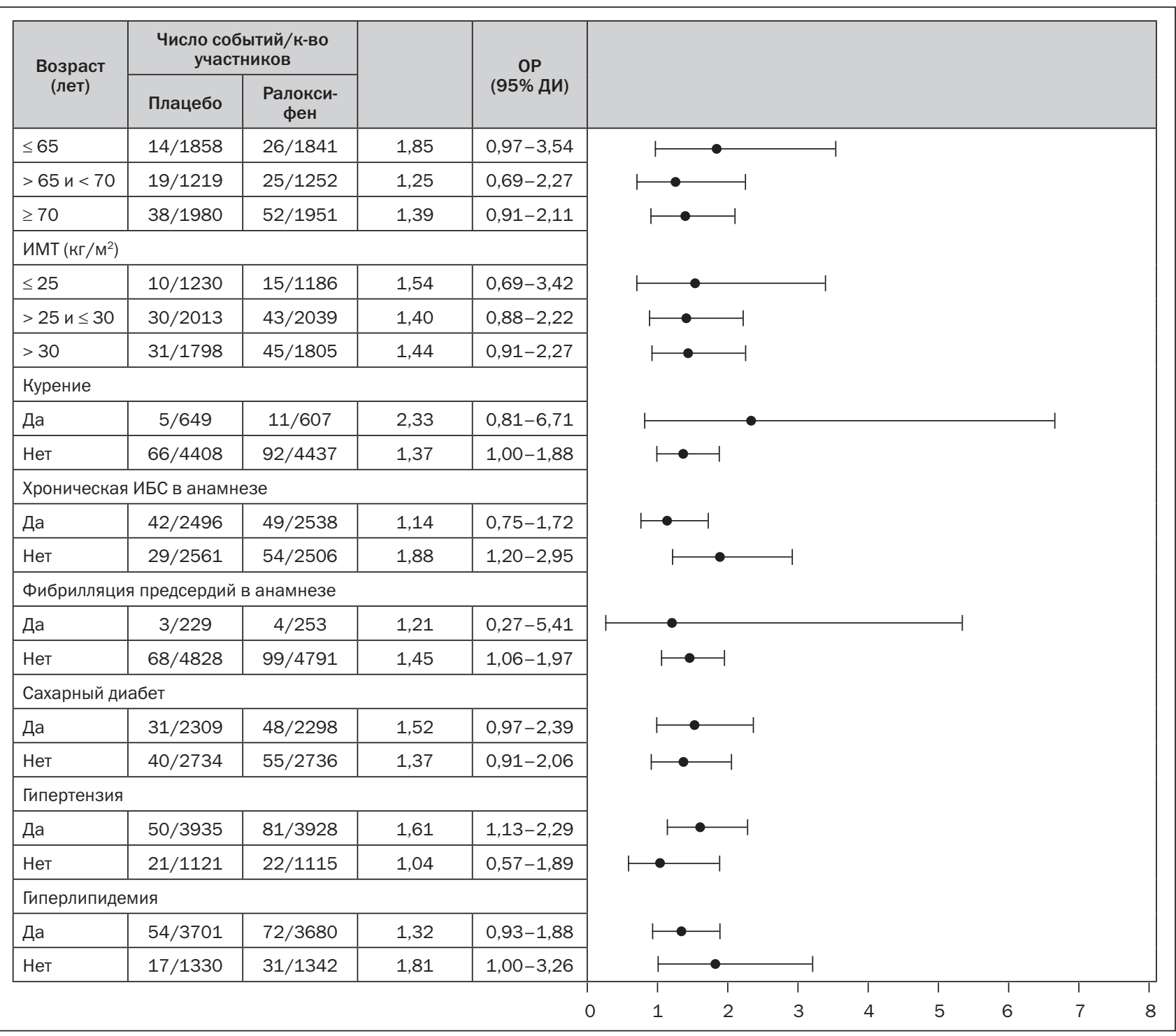

Рисунок 4. Относительный риск ВTЭ в зависимости от дополнительных факторов риска в исследовании RUTH 
Уровень ВТЭ составил в группе пациентов, принимавших стронция ранелат на момент осмотра или в прошлом, соответственно 6,8 и 7,0 на 1000 пациенто-лет $(\mathrm{HR}=0,90 ; 95 \%$ ДИ 0,46-1,75), аналогичные результаты были получены и при использовании алендроната натрия (6,2 и 7,2 на 1000 пациенто-лет; $\mathrm{HR}=0,99 ; 95 \%$ ДИ 0,80-1,23).

В марте 2012 года Европейское агентство по контролю за лекарственными средствами (ЕМЕА) обновило свое заключение в отношении эффективности и безопасности стронция ранелата, сделав заключение о том, что оно подтверждает преобладание показателя «польза - риск» для препарата, однако обращает внимание на незначительные противопоказания к его применению - инциденты ВТЭ в анамнезе и на момент назначения, включая ТГВНК и
ЛЭ, а также длительное использование у иммобилизированных пациентов. Также среди особых предостережений при использовании стронция ранелата отмечено: в связи с тем фактом, что частота ВТЭ увеличивается с возрастом, при лечении пациентов старше 80 лет следует более тщательно подходить к выбору и мониторингу терапии [14].

Таким образом, анализ существующих литературных данных свидетельствует о том, что риск ВТЭ значимо увеличивается с возрастом, а у больных остеопорозом он достоверно выше по сравнению с показателями здоровых пациентов. Некоторые антиостеопоротические препараты могут влиять на увеличение риска ВТЭ, в связи с чем важно учитывать противопоказания к их применению и факторы риска, влияющие на развитие данного осложнения.

\section{Таблица 4. Относительный риск венозных тромбоэмболий при использовании различных} антиостеопоротических препаратов [21]

\begin{tabular}{|l|c|c|c|c|c|}
\hline \multicolumn{1}{|c|}{$\begin{array}{c}\text { Неблагоприятное событие/ } \\
\text { Время регистрации }\end{array}$} & $\mathbf{N}$ & $\begin{array}{c}\text { N (в начале } \\
\text { исследования) }\end{array}$ & $\begin{array}{c}\text { N (в динамике } \\
\text { наблюдения) }\end{array}$ & OP & $95 \%$ ди \\
\hline Венозные тромбоэмболин* (стронция ранелат) & 37 & 35 & 2 & 1,1 & $0,2-5,0$ \\
\hline Венозные тромбоэмболин* (ралоксифен) & 55 & 40 & 15 & 4,7 & $1,6-13,0$ \\
\hline
\end{tabular}

Примечание: * - модель с учетом факта первой ВТЭ.

Таблица 5. Частота ВТЭ у пациентов с остеопорозом, получавших стронция ранелат или алендронат натрия, по сравнению с нелечеными пациентками с остеопорозом [8]

\begin{tabular}{|c|c|c|c|}
\hline \multirow{2}{*}{ Показатели } & \multicolumn{2}{|c|}{ Леченые пациенты с остеопорозом } & \multirow{2}{*}{$\begin{array}{c}\text { Нелеченые пациенты } \\
\text { с остеопорозом }(n=11546)\end{array}$} \\
\hline & Стронция ранелат $(\mathrm{n}=2408)$ & Алендронат натрия (n = 20 084) & \\
\hline Больные с ВТЭ (n) & 13 & 140 & 61 \\
\hline $\begin{array}{l}\text { Ежегодная заболеваемость } \\
\text { (на } 1000 \text { пациенто-лет) }\end{array}$ & 7,0 & 7,2 & 5,6 \\
\hline \multicolumn{4}{|c|}{ Модель, корригированная по возрастуа } \\
\hline HR (станд. ошибка) & $1,15(0,31)$ & $1,10(0,16)$ & \\
\hline 95\% доверительный интервал & $0,63-2,10$ & $0,81-1,50$ & \\
\hline Р-значение & 0,656 & 0,530 & \\
\hline \multicolumn{4}{|c|}{ Полностью корригированная модель } \\
\hline HR (станд. ошибка) & $1,09(0,31)$ & $0,92(0,19)$ & \\
\hline 95\% доверительный интервал & $0,60-2,01$ & $0,63-1,33$ & \\
\hline Р-значение & 0,773 & 0,646 & \\
\hline
\end{tabular}

Примечания: ВТЭ — венозная тромбоэмболия (в т.ч. тромбоз глубоких вен, тромбоэмболия легочной артерии или тромбоз вен сетчатки); HR - отношение рисков; $H R^{a}$ - между группами на основании регрессионной Сох-модели, корригированной по возрасту; $\mathrm{R}^{b}$ - между группами на основании регрессионной Сох-модели, корригированной по всем изучаемым факторам.

Таблица 6. Частота ВТЭ у пациентов, использующих препараты стронция ранелата или алендроната натрия на момент обследования, по сравнению с пациентами, не применявшими их [8]

\begin{tabular}{|c|c|c|c|c|}
\hline \multirow{3}{*}{ Показатели } & \multicolumn{4}{|c|}{ Леченые пациенты с остеопорозом } \\
\hline & \multicolumn{2}{|c|}{ Стронция ранелат ( $n=2408)$} & \multicolumn{2}{|c|}{ Алендронат натрия ( $\mathrm{n}=20084)$} \\
\hline & Использование в прошлом & Прием в настоящем & Использование в прошлом & Прием в настоящем \\
\hline Больные с ВТЭ (n) & 34 & 13 & 230 & 140 \\
\hline $\begin{array}{l}\text { Ежегодная заболеваемость } \\
\text { (на } 1000 \text { пациенто-лет) }\end{array}$ & 6,8 & 7,0 & 6,2 & 7,2 \\
\hline HR (станд. ошибка) & \multicolumn{2}{|c|}{$0,90(0,34)$} & \multicolumn{2}{|c|}{$0,99(0,11)$} \\
\hline 95\% доверительный интервал & \multicolumn{2}{|c|}{$0,46-1,75$} & \multicolumn{2}{|c|}{$0,80-1,23$} \\
\hline Р-значение & \multicolumn{2}{|l|}{0,75} & \multicolumn{2}{|l|}{0,96} \\
\hline
\end{tabular}




\section{Список литературы}

1. Макацария А.Д., Бицадзе В.О.Заместительная гормональная терапия: «за и против». http://www.medlinks.ru/ article.php?sid=9183.

2. Медицина климактерия / Под ред. В.П. Сметник. М., 2006. - 847 c.

3. Поворознюк В.В., Григорьева Н.В. Менопауза и костно-мышечная система. - К.: Експрес, 2004. - 512 с.

4. Baglin T., Luddington R., Brown K., Baglin C. Incidence of recurrent venous thromboembolism in relation to clinical and thrombophilic risk factors: prospective cohort study // Lancet. - 2003. - 362. - P. 523-526.

5. Bolland M.J., Avenell A., Baron J.A. et al. Effect of calcium supplements on risk of myocardial infarction and cardiovascular events: meta-analysis // BMJ. - 2010. - 341. - P. 3691.

6. Bolland M.J., Grey A., Avenell A. et al. Calcium supplements with or without vitamin D and risk of cardiovascular events: reanalysis of the Women's Health Initiative limited access dataset and meta-analysis // BMJ. - 2011. - 342. - d2040.

7. Bolland M.J., Barber P.A., Doughty R.N. et al. Vascular events in healthy older women receiving calcium supplementation: randomised controlled trial // BMJ. - 2008. - 336. P. 262-266

8. Breart G., Cooper C., Meyer O. et al. Osteoporosis and venous thromboembolism: a retrospective cohort study in the UK General Practice Research Database // Osteoporos. Int. 2010. - 21(7). - P. 1181-1187.

9. Cigolini M., Iagulli M.P., Miconi V. et al.Serum 25-hydroxyvitamin $\mathrm{D}_{3}$ concentrations and prevalence of cardiovascular disease among type 2 diabetic patients // Diabetes Care. 2006. - 29. - P. 722-724.

10. Clarke S.C., Kelleher J., Lloyd-Jones H. et al. A study of hormone replacement therapy in postmenopausal women with ischaemic heart disease: the Papworth HRT atherosclerosis study // BJOG. - 2002. - 109. - P. 1056-1062.

11. Clinical trials of hormonal replacement therapy for cardiovascular prevention in all type of patients. - http://www trialresultscenter.org/textify_t/452-cardiovascular\%20prevention-hormonal\%20 replacement\%20therapy.pdf

12. Cushman M., Albert W., Tsai, Richard H. et al. Deep Vein Thrombosis and Pulmonary Embolism in Two Cohorts: The Longitudinal Investigation of Thromboembolism Etiology // American Journal of Medicine. - 2004. - 117. - P. 19-25.

13. Cushman M., Legault C., Barrett-Connor E. et al. Effect of postmenopausal hormones on inflammation-sensitive proteins: the Postmenopausal Estrogen/Progestin Interventions (PEPI) Study // Circulation. - 1999. - 100. - P. 717-722.

14. EMEA Press Release 2012. [last accessed: 15.03.2012] http://www.ema.europa.eu/docs/en_GB/document_library/ Medicine_QA/2012/03/WC500124208.pdf.

15. ESPRIT Team. Oestrogen therapy for prevention of re-infarction in postmenopausal women: a randomized controlled trial // Lancet. - 2002. - 359. - P. 2001-2008.

16. Fimognari F.L., Repetto L., Moro L. et al. Age, cancer, and the risk of venous thromboembolism // Crit. Rev. Oncol. Hematol. - 2005. - 55. - P. 207-212.

17. General Practice Research Database. - http://www.gprd. com/home.

18. Gomez M., Deitcher S. Risk of venous thromboembolic disease associated with hormonal contraceptives and hormone replacement therapy: a clinical review // Archives of Internal Medicine. - 2004. - 164. - P. 1965-1976.

19. Grady D., Ettinger B., Moscarelli E. et al. Multiple Outcomes of Raloxifene Evaluation Investigators Safety and adverse effects associated with raloxifene: Multiple outcomes of raloxifene evaluation // Obstet. Gynecol. - 2004. - 104. - P. 837-844.

20. Grady D., Wenger N., Herrington D. et al. Postmenopausal hormone therapy increases risk for venous thromboembolic disease. The Heart and Estrogen/progestin Replacement Study //Annals of Internal Medicine. - 2000. - 132. P. 689-696.

21. Grosso A., Douglas I., Hingorani A. et al. Post-marketing assessment of the safety of strontiumranelate; a novel case-only approach to the early detection of adverse drug reactions $/ / \mathrm{Br}$. J. Clin. Pharmacol. - 2008. - 66(5). - P. 689-694.

22. Heit J., Cohen A., Anderson F.J. Estimated annual number of incident and recurrent, non-fatal and fatal venous thromboembolism (VTE) events in the US // Blood. - 2005. - 106. - P. 267A.

23. Heit J., Kobbervig C., James A. et al. Trends in the incidence of deep vein thrombosis and pulmonary embolism during pregnancy or the puerperium: A 30-year population-based study // Annals of Internal Medicine. - 2005. - 143. - P. 697-706.

24. Heit J., Mohr D., Silverstein M. et al. Predictors of recurrence after deep vein thrombosis and pulmonary embolism: a population-based cohort study // Archives of Internal Medicine. 2000. - 160. - P. 761-768.

25. Heit J., Petterson T., Farmer S. et al. Trends in Incidence of deep vein thrombosis and pulmonar embolism: a 35-year population-based study // Blood. - 2006. - 108. - P. 430a.

26. Heit J., Silverstein M., Mohr D. et al. Predictors of survival after deep vein thrombosis and pulmonary embolism: a population-based, cohort study // Archives of Internal Medicine. 1999. - 159. - P. 445-453.

27. Heit J.A. The epidemiology of venous thromboembolism in the community // Arterioscler. Thromb. Vasc. Biol. - 2008. 28. - P. 370-372.

28. Heit J.A. Venous thromboembolism epidemiology: implications for prevention and management // Semin. Thromb. Hemost. - 2002. - 28 (Suppl. 2). - P. 3-13.

29. Heit J.A., Silverstein M.D., Mohr D.N. et al. The epidemiology of venous thromboembolism in the community // Thromb. Haemost. - 2001. - 86. - P. 452-463.

30. Hoibraaten E., Qvigstad E., Arnesen H. et al. Increased risk of recurrent venous thromboembolism during hormone replacement therapy. Results of the randomized, double-blind, placebocontrolled estrogen in venous thromboembolism trial (EVTET) // Thromb. Haemost. - 2000. - 84. - P. 961-967.

31. Holmberg L., Anderson H. for the HABITS steering and data monitoring committees. HABITS (hormonal replacement therapy after breast cancer-is it safe?), a randomised comparison: trial stopped // Lancet. - 2004. - 363. - P. 453-455.

32. Hooper W., Holman R., Heit J., Cobb N. Venous thromboembolism hospitalizations among American Indians and Alaska Natives // Thrombosis Research. - 2002. - 108. - P. 273-278.

33. Hulley S., Grady D., Bush T. et al. Randomized trial of estrogen plus progestin for secondary prevention of coronary heart disease in postmenopausal women. Heart and Estrogen/progestin Replacement Study (HERS) Research Group // JAMA. 1998. - 280. - P. 605-613.

34. Janata K., Holzer M., Domanovits H. et al. Mortality of patients with pulmonary embolism // Wiener Medizinische Wochenschrift. - 2002. - 114. - P. 766-772.

35. Kearon C., Gent M., Hirsch J. et al. A comparison of three months of anticoagulation with extended anticoagulation for a first episode of idiopathic venous thromboembolism // New England Journal of Medicine. - 1999. - 340. - P. 901-907.

36. Kesteven P.J.L. Traveller's Thrombosis // Thorax. 2000. - 55(Suppl. 1). - S. 32-36.

37. Koh K.K., Horne M.K. III, Cannon R.O. III. Effects of hormone replacement therapy on coagulation, fibrinolysis, and thrombosis risk in postmenopausal women // Thromb. Haemost. - 1999. - 82. - P. 26-33.

38. Kwong L.M. Hip fracture and venous thromboembolism in the elderly // J. Surg. Orthop. Adv. - 2004. - 13. - P. 139-148.

39. Kyrle P.A., Eichinger S. Venous thromboembolism in men and women // J. Men's Health \& Gender. - 2005. - 2. P. 302-308.

40. LaCroix A.Z., Kotchen J., Anderson G. et al.Calcium plus vitamin D supplementation and mortality in postmenopausal women: the Women's Health Initiative calcium-vitamin D randomized controlled trial // J. Gerontol. A Biol. Sci Med. Sci. 2009. - 64(5). - P. 559-567.

41. Lee J.H., O'Keefe J.H., Bell D. et al. Vitamin D Deficiency. An Important, Common, and Easily Treatable Cardiovascular Risk Factor? // J. Am. Coll. Cardiol. - 2008. - 52(24). P. 1949-1956. 
42. Lewis J.R., Calver J., Zhu K. et al. Calcium supplementation and the risks of atherosclerotic vascular disease in older women: results of a 5-year RCT and a 4.5-year follow-up // J. Bone Miner. Res. - 2011. - 26. - P. 35-41.

43. Machlus K.R., Aleman M.M., Wolberg A.S. Update on Venous Thromboembolism: Risk Factors, Mechanisms, and Treatments // Arterioscler. Thromb. Vasc. Biol. - 2011. - 31(3). P. 476-478.

44. Manson J.E., Hsia J., Johnson K.C. et al. Estrogen plus progestin and the risk of coronary heart disease // N. Engl. J. Med. 2003. - 349. - P. 523-534.

45. Martins D., Wolf M., Pan D. et al. Prevalence of cardiovascular risk factors and the serum levels of 25-hydroxyvitamin D in the United States: data from the Third National Health and Nutrition Examination Survey // Arch. Intern. Med. - 2007. - 167. P. 1159-1165.

46. McRae S., Tran H., Schulman S. et al. Effect of patient's sex on risk of recurrent venous thromboembolism: a meta-analysis // Lancet. - 2006. - 368. - P. 371-378.

47. Melamed M.L., Muntner P., Michos E.D. et al. Serum 25-hydroxyvitamin D levels and the prevalence of peripheral arterial disease. Resultsfrom NHANES 2001 to 2004 // Arterioscler. Thromb. Vasc. Biol. - 2008. - P. 1179-1185.

48. Michaëlsson K., Melhus H., Lemming E.W. et al. Long term calcium intake and rates of all cause and cardiovascular mortality: community based prospective longitudinal cohort study // BMJ. - 2013. - 346doi: http://dx.doi.org/10.1136/bmj.f228.

49. Mosca L., Grady D., Barrett-Connor E. et al. Effect of Raloxifene on Stroke and Venous Thromboembolism According to Subgroups in Postmenopausal Women at Increased Risk of Coronary Heart Disease // Stroke. - 2009. - 40(1). - P. 147-155.

50. Palareti G., Cosmi B., Legnani C. et al. D-Dimer Testing to Determine the Duration of Anticoagulation Therapy // N. Engl. J. Med. - 2006. - 355. - P. 1780-1789.

51. Poole K.E., Loveridge N., Barker P.J. et al. Reduced vitamin D in acute stroke // Stroke. - 2006. - 37. - P. 243-245.

52. Popuri R.K., Vedantham S. The role of thrombolysis in the clinical management of DVT // Arterioscler. Thromb. Vasc. Biol. -2011 .

53. Prandoni P., Lensing A.W., Prins M.H. et al. Residual venous thrombosis as a predictive factor of recurrent venous thromboembolism // Ann. Intern. Med. - 2002. - 137(12). - P. 955960 .

54. Reginster J.Y. et al. Osteoporos Int. - 2011. - 22 (Suppl. 1). - S. 110-111, OC32.

55. Riggs B., Hartmann L. Selective Estrogen-Receptor Modulators // N. Engl. J. Med. - 2003. - 348. - P. 618-629.

56. Rosendaal F.R. Risk factors for venous thrombotic disease // Thromb. Haemost. - 1999. - 82. - P. 610-619.

57. Rosendaal F.R., HylckamaVlieg A., Doggen C.J. Venous thrombosis in the elderly // J. Thromb. Haemost. - 2007. 5(Suppl. 1). - P. 310-317.

58. Rosendaal F.R., Van HylckamaVlieg A., Tanis B.C., Helmerhorst F.M. Estrogens, progestogens and thrombosis // J. Thromb. Haemost. - 2003. - 1. - P. 1371-1380.

59. Rosendaal F.R., Vessey M., Rumley A. et al. Hormonal replacement therapy, prothrombotic mutations and the risk of venous thrombosis // Br. J. Haematol. - 2002. - 116. P. 851-854

60. Rossouw J.E., Anderson G.L., Prentice R.L. et al. Writing Group for the Women's Health Initiative Investigators Risks and benefits of estrogen plus progestin in healthy postmenopausal women: principal results from the Women's Health Initiative randomized controlled trial // JAMA. - 2002. 288. - P. 321-333.

61. Schulman S., Svenungsson E., Granqvist S. Anticardiolipin antibodies predict early recurrence of thromboembolism and death among patients with venous thromboembolism following anticoagulant therapy. Duration of Anticoagulation Study Group // American Journal of Medicine. - 1998. - 104. - P. 332-338

62. Schulman S., Lindmarker P., Holmstrom M. et al. Postthrombotic syndrome, recurrence, and death 10 years after the first episode of venous thromboembolism treated with warfarin for 6 weeks or 6 months // Journal of Thrombosis and Haemostasis. 2006. - 4. - P. 732-742.

63. Scragg R., Jackson R., Holdaway I.M. et al. Myocardial infarction is inversely associated with plasma 25 -hydroxyvitamin $\mathrm{D}_{3}$ levels: a community-based study // Int. J. Epidemiol. — 1990. 19. - P. 559-563.

64. Shah S.M., Carey I.M., Harris T. et al. Calcium supplementation, cardiovascular disease and mortality in older women // Pharmacoepidemiol. Drug Saf. - 2010. - 19(1). - P. 59-64.

65. Silverstein M., Heit J., Mohr D. et al. Trends in the incidence of deep vein thrombosis and pulmonary embolism: a 25-year population-based, cohort study // Archives of Internal Medicine. - 1998. - 158. - P. 585-593.

66. Silverstein R.L., Bauer K.A., Cushman M. et al. Venous thrombosis in the elderly: more questions than answers // Blood. - 2007. - 110. - P. 3097-3101.

67. Spencer F.A., Emery C., Lessard D. et al. The Worcester Venous Thromboembolism Study A Population-Based Study of the Clinical Epidemiology of Venous Thromboembolism // J. Gen. Intern. Med. - 2006. - 21(7). - P. 722-727.

68. Spyropoulos A.C., Lin J. Direct medical costs of venous thromboembolism and subsequent hospital readmission rates: an administrative claims analysis from 30 managed care organizations // J. Manag. Care Pharm. - 2007. - 13. - P. 475-486.

69. Stefanick M.L. Risk-benefit profiles of raloxifene for women // N. Engl. J. Med. - 2006. - 355. - P. 190-192.

70. Symington I.S., Stack B.H.R. Pulmonary thromboembolism after travel // Br. J. Chest. - 1977. - 17. - P. 138-140.

71. Teede H.J., McGrath B.P., Smolich J.J. et al. Postmenopausal hormone replacement therapy increases coagulation activity and fibrinolysis // Arterioscler. Thromb. Vasc. Biol. - 2000. 20. - P. 1404-1409.

72. Van den Belt A., Sanson B.-J., Simioni P. et al. Recurrence of venous thromboembolism in patients with familial thrombophilia // Archives of Internal Medicine. - 1997. 157. - P. 227-232.

73. Van Dongen C., Vink R., Hutten B. et al. The incidence of recurrent venous thromboembolism after treatment with vitamin $\mathrm{K}$ antagonists in relation to time since first event: a meta-analysis // Archives of Internal Medicine. - 2003. - 163. P. 1285-1293.

74. Veerus P., Hovi S., Fischer K. et al. Results from the Estonian postmenopausal hormone therapy trial // Maturitas. 2006. - 55. - P. 162-173

75. Vickers M.R., MacLennan A.H., Lawton B. et al. Main morbidities recorded in the women's international study of long duration oestrogen after menopause (WISDOM): a randomised controlled trial of hormone replacement therapy in postmenopausal women // BMJ. - 2007. - 4. - 335(7613). - P. 239.

76. Viscoli C.M., Brass L.M., Kernan W.N. et al. A clinical trial of estrogen-replacement therapy after ischemic stroke // N. Engl. J. Med. - 2001. - 345. - P. 1243-1249.

77. Waters D.D., Alderman E.L., Hsia J. et al. Effects of hormone replacement therapy and antioxidant vitamin in postmenopausal supplements on coronary atherosclerosis in postmenopausal women: a randomized controlled trial // JAMA. - 2002. 288. - P. 2432-2440.

78. White R., Zhou H., Romano P. Incidence of idiopathic deep venous thrombosis and secondary thromboembolism among ethnic groups in California // Annuals of Internal Medicine. 1998. - 128. - P. 737-740.

79. White R.H. The epidemiology of venous thromboembolism // Circulation. - 2003. - 107. - P. 14-18.

80. Women's Health Initiative Steering Committee. Effects of conjugated equine estrogen in postmenopausal women with hysterectomy. The women's health initiative randomised controlled trial // JAMA. - 2004. - 291. - P. 1701-1712.

81. Writing Group for the Women's Health Initiative Investigators. Risks and benefits of estrogen plus progestin in healthy postmenopausal women. Principal results from the women's health initiative randomized controlled trial // JAMA. -2002 . - 288. P. 321-333.

Получено 08.02.13 